\title{
FLEX-FUEL SMART SELECTOR, THE PERSONAL CONTRIBUTION TO THE MOBILITY OF TOMORROW IN BRAZIL
}

\author{
Vitor Costa Antonelli Correia, Paulo César de Ferreira Gomes e Erwin Karl Franieck \\ Robert Bosch Ltda \\ E-mails: fixed-term.vitor.correia4@br.bosch.com,paulo.gomes@br.bosch.com e \\ erwin.franieck@br.bosch.com
}

\begin{abstract}
Society is changing its behavior due to the growing concern about the environmental impact caused by humans. Given the number of vehicles in the world, mobility is on the spotlight since any improvement in vehicle efficiency results in a large reduction in the emission of greenhouse gases. In Brazil, biofuels are an alternative but these still face difficulties to gain users' preference. This is mainly due to the price parity between ethanol and gasoline, coupled with the nescience of which fuel has the lowest cost per kilometer traveled and the misinformation regarding the difference in environmental impact generated when compared to fossil fuels, since ethanol has a minor impact to the environment even than electric vehicles, considering the entire production chain. The work here described presents a proposal to provide to the user more accurate information about the average consumption of his vehicle allowing the fuel choice to be more efficient and expose the impact caused in terms of $\mathrm{CO}_{2}$ emitted given the fuel used. This is done by continuously gathering vehicle's data through the CAN bus, processing it in the cloud and then relaying it to the user. This allows the driver to contribute directly to socio-environmental well-being by managing the volume of fossil fuel consumed.
\end{abstract}

\section{INTRODUCTION}

Social and environmental concerns are gaining visibility in the world, given the increasing evidence of the impact generated by the humankind with the extensive use of available natural resources. There is a great discussion about the generation and the efficient use of the available energy matrix, in this sense the questions related to the mobility have been debated mainly with respect to the internal combustion engines. According to data from the International Energy Agency (IEA) [1] and the World Energy Council [2], the use of petroleum products within the transport sector accounts for $26 \%$ of the world energy matrix, which shows that society is deeply dependent on fuels fossil.

Considering the problem in question, several alternatives have been studied and implemented in the world, such as electric vehicles or fuel cell, but all those technologies have positive and negative points that must be weighed within the perspective of each country and its socioeconomic situation. An efficient and cost-effective alternative is the use of biofuels, Brazil is an example of a country where ethanol has a good market acceptance since approximately $70 \%$ [3] of the vehicle fleet consists of Flex-Fuel vehicles, that is, they can use both ethanol and gasoline. However, according to data from the National Petroleum Agency (ANP) [4], 
ethanol represents only $10 \%$ of the national vehicle energy matrix, while commercial gasoline accounts for $32 \%$ of the Brazilian market, which shows that ethanol still does not have the preference of consumers.

Brazilian government made at the 21st Conference of Parties of the United Nations Framework Convention on Climate Change (COP21) a commitment of reducing GHG emissions of $43 \%$ by 2030 in relation to 2005 . This target depends on increasing the participation of bioenergy in the national energy matrix to reach $18 \%$ in 2030 [5]. In this way, there is a need of a joint effort between the government, industry and individuals in which each sphere has an important role to play.

The government sphere is responsible for establishing regulatory laws on emissions generated by motor vehicles, laws to encourage the use of technologies that are more efficient, promoting research and developing programs such as the RenovaBio and Rota 2030, as well as overseeing the other spheres. The industrial sphere is responsible for following the laws and norms determined by governmental institutions, investing in research and developing technologies that reduce the environmental impact generated by the production and use of the automotive vehicles and also for creating and maintaining social and environmental programs in the communities in which they are inserted. The last sphere is society, the users, whom are responsible for verifying if the other spheres play their roles and for using their vehicle consciously, efficiently, and ecologically. However, it is possible to realize that the user still lacks the tools and information that allow him to make better decisions about the use of his vehicle. In this way, it is clear the necessity for the creation, implementation and use of tools to help them with a reliable base of information.

\section{EXPERIMENTAL METHODS AND EQUIPMENTS}

In order to understand the customer's behavior at the time of refueling, how they choose the fuel, what influences the user to prefer a fuel to the others, an ethnographic research process was carried out. The information that was gathered led to the creation of a hardware prototype and software that will be presented in the sequence.

\subsection{ETNOGRAPHIC RESEARCH}

As mentioned above, an ethnographic field survey was conducted with more than 80 interviews involving end-users, station owners, fleet managers, and fuel distribution company employees. This process was carried out in order to better understand the behavior of the national fuel market and thus propose a tool with a consumer-centered design.

The process can be divided into two distinct phases, the first one composed of the interviews in the field that aim to collect the information, opinions and mainly the complaints of the interviewees regarding the subject raised in this case: how does the consumer choose between gasoline and ethanol. After the various interviews and the amount of information collected, we move on to a phase of grouping information in which the topics mentioned in several interviews are considered more relevant because they are probably not individual problems, but general. At the end of this second stage, the initial proposal was redesigned based on the factors considered as very important in the interviews and the grouping of information. 


\subsection{PROPOSED TOOL}

At the end of the process of ethnographic research and clustering of the information collected, it was identified that the consumer faces two dilemmas at the time of refueling that may influence his choice of fuel. The first question is about the efficiency of the vehicle with different fuels, today, in some states, gas stations are obliged by law to inform consumers of the price parity between ethanol and commercial gasoline, Figure 1 exemplifies how this report is made in some establishments. Using the price parity reported by the establishment, the consumer often uses the $70 \%$ paradigm, which says that if price parity is above $70 \%$, commercial gasoline has an economic advantage. However, this relation is not a universal truth, since the ratio between consumption with ethanol and gasoline may vary depending on the vehicle-driver pair, as it is influenced by the state of maintenance of the vehicle, driving style, traffic conditions and the quality of the fuel used [6].

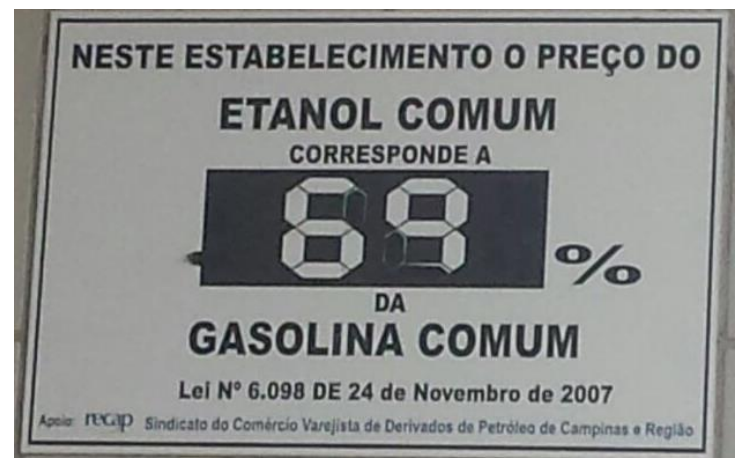

Figure 1. Example of a plate informing the fuel price parity in a gas station

Another point that consumers pointed out was the quality of the fuel found at the gas stations. The driver often feels quaky at the time of fueling in relation to the possibility of contamination of the fuel he is fueling. As it was observed, part of this discomfort is because the citizen questions the effectiveness of the inspections carried out by the regulatory agencies, either by the low frequency of visits by the agents, or by the total number of visits, among others. 


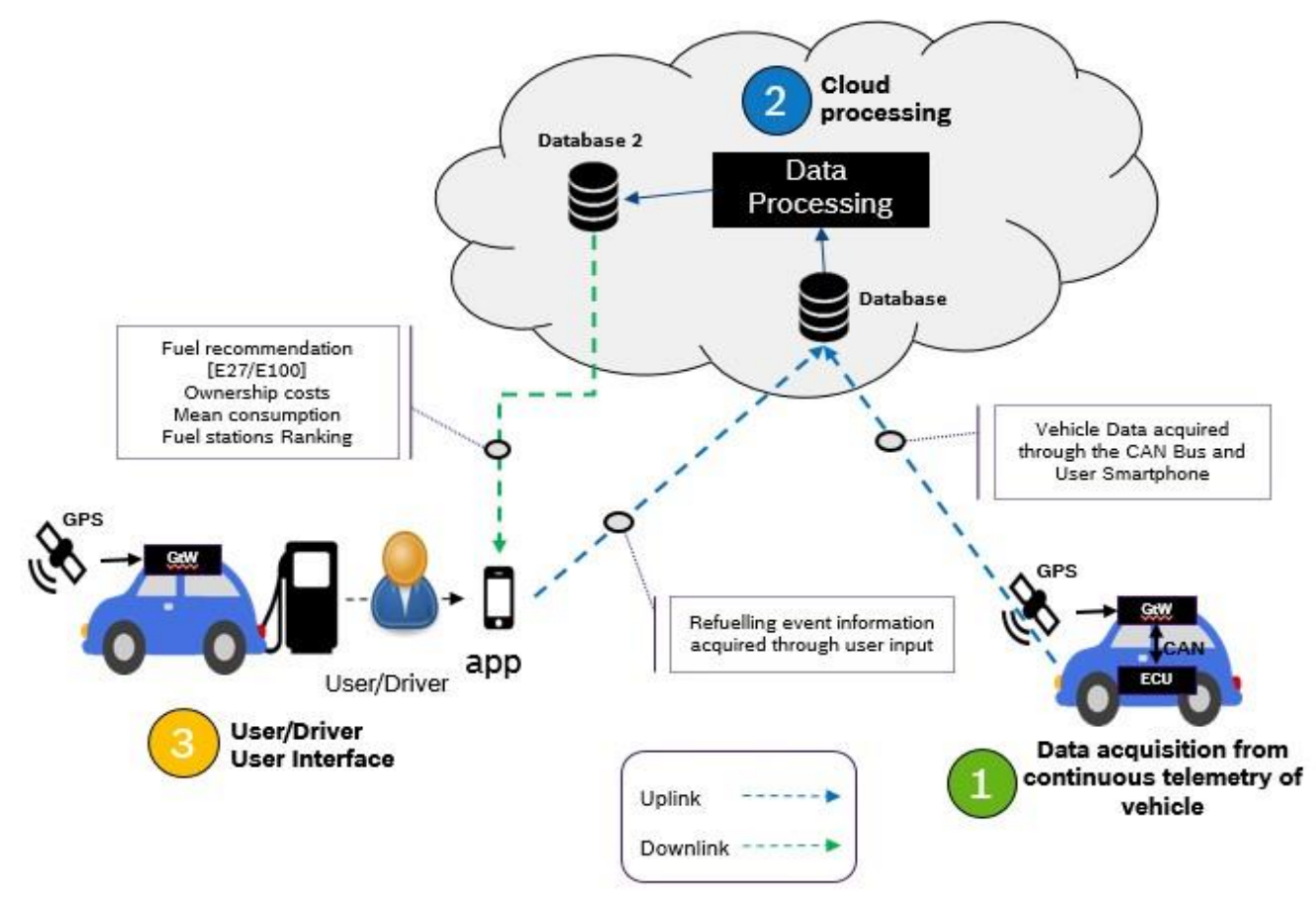

Figure 2. An overview summary on where information is collect, process and to where it is displayed

The proposed tool can be divided in four major components: a dongle that goes connected to the OBD port, a smartphone, a mobile application and a cloud system, those components are better detailed in the following sections.

\subsubsection{Hardware}

The hardware is divided into two parts, first there is a dongle that is connected to the OBD port that is composed by some electronic components responsible for communicating and interpreting the information that transit the CAN Network of the vehicle. A microprocessor with a Bluetooth module is responsible for local processing of part of the data acquired through the CAN bus and sending the information to the smartphone, as shown in Figure 3. The smartphone is the second part of the hardware, in which the information is stored until there is a GSM connection to send the data to the cloud and after processing these data are retransmitted to the user's smartphone where they are stored so that they are always available to the driver.

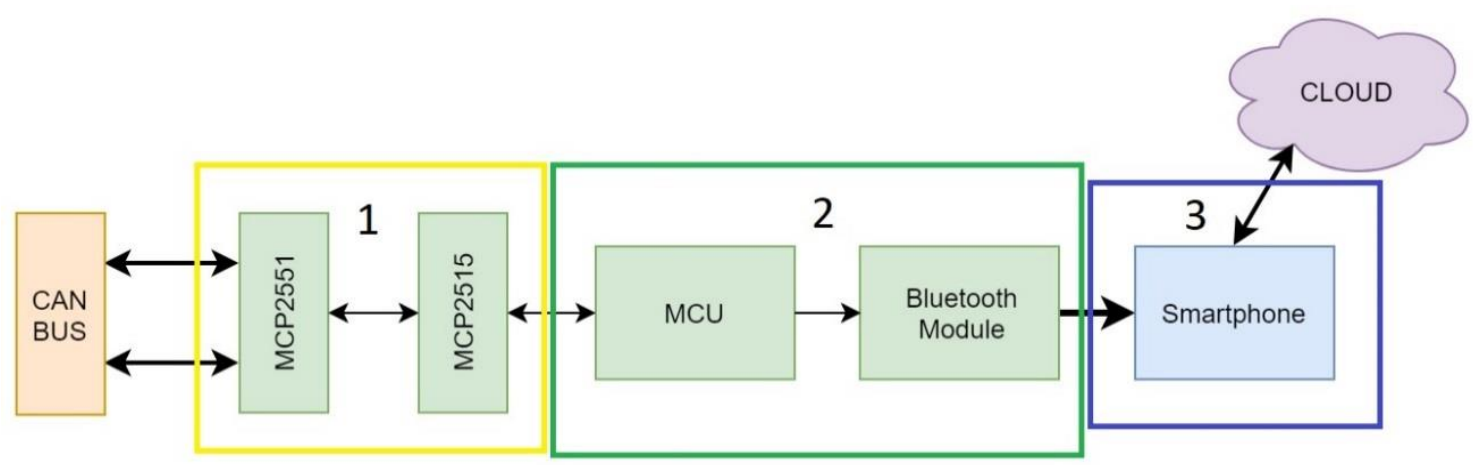

Figure 3. Hardware layout summary - (1) is where the CAN messages are transmitted and received; (2) is the microcontroller and the Bluetooth module and (3) is the Smartphone 
Figure 4 shows one of the prototypes of hardware built in a "homemade" way for validating the concepts created and testing of the developed algorithms. After the validation of the results and concepts, a hardware improvement phase will be carried out in order to make it more compact.

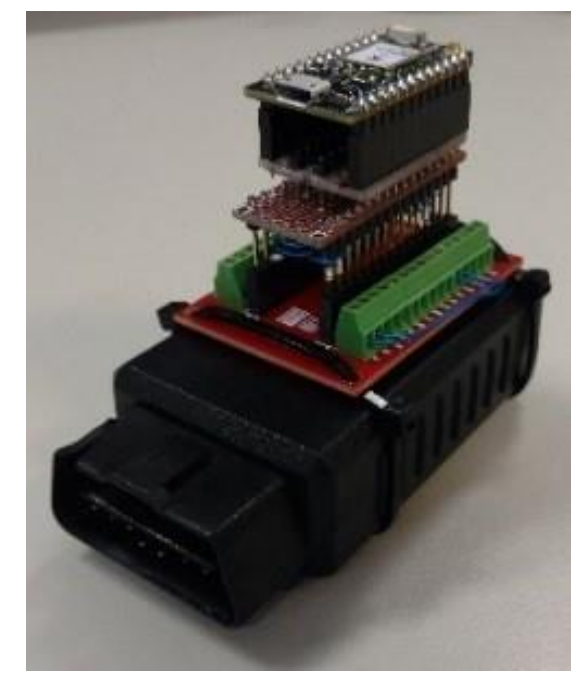

Figure 4. Handmade Dongle prototype

\subsubsection{Mobile Application}

The tool was designed for the user's smartphone, since it is an item very common in the daily lives of people and is very versatile. The smartphone was included in the design of the tool because it is the communication gateway between the dongle and the cloud, where data is processed. With this in mind, a mobile application was developed that will connect with the dongle and the cloud to provide information to the user, as well as being the point of information availability for the user.

The application also serves as a database for the data when there is no network connection to the cloud, since there are areas within the national territory that have a low quality GSM signal or also in cases where user do not want to spend their mobile data plan for data transmission. The application has several tabs where the information is presented, one of the tabs contain specific travel information, which can be chosen in a calendar, among the information on this tab are distance traveled, fuel consumed, average speed, maximum speed, travel route on a map, among others as shown in Figure 5. Another tab shows the economy generated by the user's fuel choices, financially and ecologically, i.e. how much money the user saved due to the use of a fuel to the detriment of another or the mass of $\mathrm{CO}_{2}$ emitted. There is also a tab indicating the average consumption for the different fuels and the ratio of consumption of the vehicle-driver pair, and another relative to the refueling event in which the fuel price values will be inserted and will return to the user the most indicated fuel from the economic point of view. 


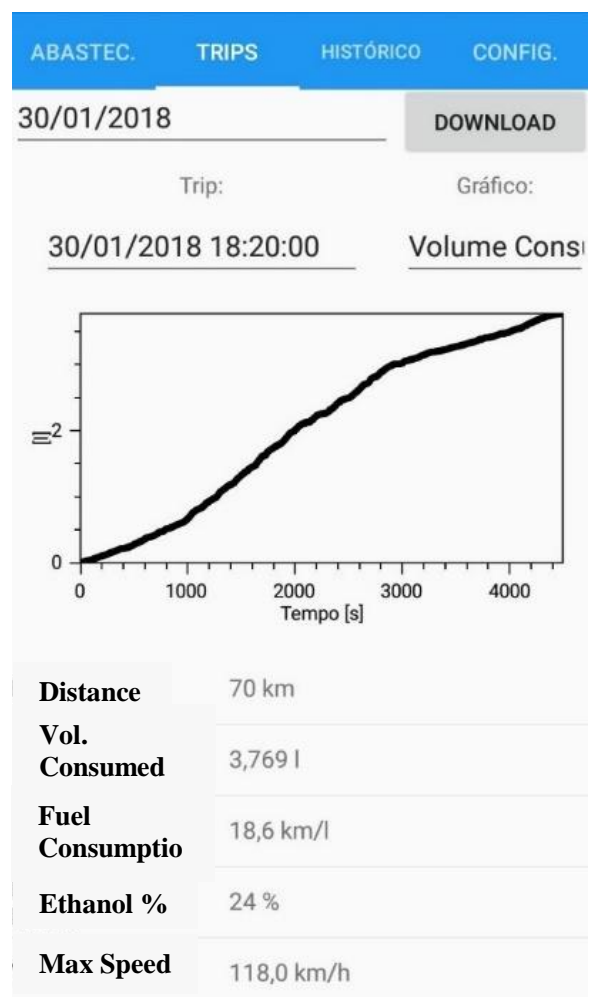

Figure 5. Tab containing trip information such as distance travelled; fuel consumed, top speed, Fuel Consumption and others.

\subsubsection{Cloud System}

After arriving in the cloud, the data is processed through a statistical analysis, which processes the fault codes found during the use of the device, the volume of fuel consumed, the distance travelled and a series of other information about the state of maintenance and use of the vehicle. This process also makes an analysis of the possible causes of the failures found through the crossing of data of the various components of the vehicle, and in the case of failures that can be originated by the poor quality of fuel occurrences in other vehicles that have their data in the cloud are taken into account.

Using the hardware and software mentioned above, it is possible to solve the problems presented above. With the acquisition and continuous analysis of vehicle information it is possible to determine the average consumption for both ethanol and commercial gasoline under various conditions of use and thus allied to fuel price parity determine which option presents the lowest cost of the kilometer travelled for the pair uservehicle. Similarly, it is possible to determine, also using the average consumption for each fuel, the mass of $\mathrm{CO}_{2}$ emitted per trip or tank of fuel and thus expose the user to the environmental impact generated by the use of his vehicle and make him aware of the issue. It is interesting to note that the developed tool continuously updates the data of average consumption through the value measured during the daily use of the vehicle. The consumption calculation also considers the different vehicle usage profiles, for example by weighing the consumption depending on the use in urban stretches (which present a high fuel consumption per kilometer traveled) and highway segments (which normally present average consumption better than measured in urban stretches). 
Another feature to assist the driver with regard to the choice of fuel concerns the quality of the fuel at the gas stations in the region where the driver is located. Since several users will be making their contribution by sending information regarding bad fuel failures to the cloud, it is possible through statistical analysis implemented in the cloud to determine a ranking of the fuel stations of that region. The continuous update of the establishment's rating is based on the existence or not of failures in other vehicles that refueled therein, as well as in the quantity and gravity of these failures.

\section{RESULTS}

\subsection{FUEL CONSUMPTION CONTINUOS UPDATE}

The average consumption of the vehicle influences the choice of the consumer when it comes to refueling the vehicle. However, as mentioned before fuel consumption is affected by several external factors, which means that the same vehicle model can present different average consumption depending on the traffic through which it travels, of the quality of the fuel they use, among others. The tool was developed to determine the average consumption of the car for ethanol and commercial gasoline and thus present to the driver a more accurate and updated value than those informed by the Brazilian Vehicle Labeling Program (PBEV) because it does take into account the environmental factors in its calculations. It is important to note that the algorithm uses the ethanol sensor to determine the fuel in the tank and take into account the consumption values only if the fuel is E100 or E25/E27 that represents ethanol, commercial and premium gasoline. This means that if the driver refuel his vehicle with different fuel types before depleting the tank the consumption data will not be taken into consideration when determining the average consumption, but it will show the mean consumption for that trip in the Trip tab as shown in Figure 5. Table 1 shows data from some vehicle models, according to the PBEV, and Figure 6 shows the data of average fuel consumption, obtained with the use of the tool described in this document, and comparing both it can be noticed that there are differences in the displayed values.

Table 1. Fuel consumption data for various vehicles - source: PBEV

\begin{tabular}{|c|c||c|c||c|}
\cline { 2 - 5 } \multicolumn{1}{c|}{} & \multicolumn{2}{c|}{ Ethanol } & \multicolumn{2}{c|}{ Comercial Gasoline } \\
\hline Vehicle & City [km/l] & Highway [km/l] & City [km/l] & Highway [km/l] \\
\hline A & 9,2 & 10,2 & 13,5 & 14,6 \\
B & 8,5 & 9,9 & 12,5 & 14,1 \\
C & 9,2 & 10,8 & 13,5 & 15,7 \\
D & 9,1 & 10,6 & 13,2 & 15,2 \\
E & 8,8 & 10,5 & 12,9 & 15 \\
F & 8,7 & 10,4 & 12,0 & 14,2 \\
\hline
\end{tabular}






Figure 6. Fuel Consumption data for Vehicle $A$ and $C$ acquired using the tool described

In the above images, it is also possible to observe that the consumption ratio, which is the ratio between average consumption with commercial gasoline and average consumption with ethanol, differs from the $70 \%$ that is usually used which could lead the consumer to a misunderstanding when refueling.

To illustrate how this difference is important, one can take the following example: say fuel prices in the region are $\mathrm{R} \$ 2.50$ per liter of ethanol and $\mathrm{R} \$ 3.52$ per liter of commercial gasoline, with these prices we have a parity of $71.02 \%$. If we compare to the value of $70 \%$ that drivers commonly use would have as a result that for this situation commercial gasoline has a commercial advantage over ethanol. However, as can be seen in Figure 7, for both vehicles the fuel that presents the lowest cost of the kilometer is ethanol, since the ratio of consumption of both vehicles is higher than $71.02 \%$.

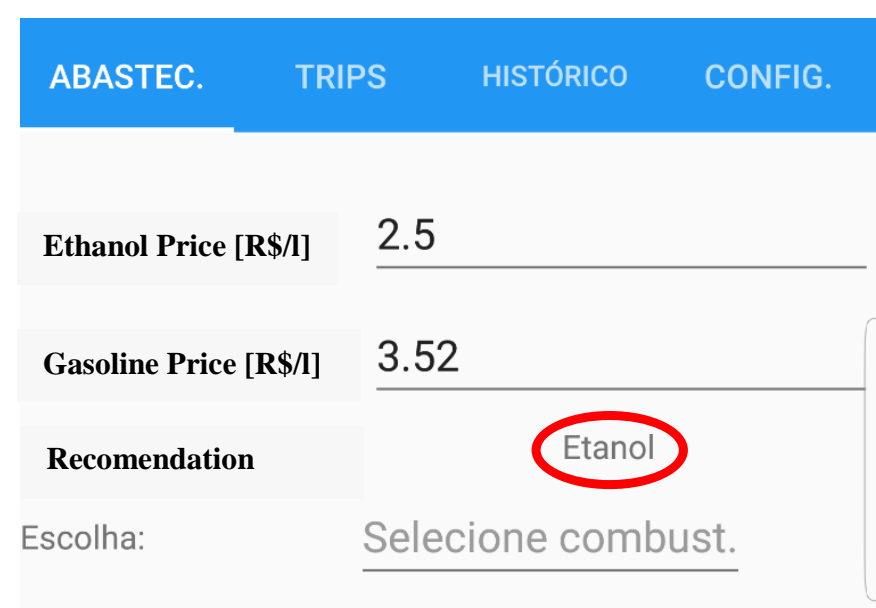

Figure 7. Indication of the most economic Fuel choice for the given prices 
Now if the fuel prices were $\mathrm{R} \$ 2.54$ per liter of ethanol and $\mathrm{R} \$ 3.49$ per liter of ordinary gasoline, the price parity is $72.78 \%$. Observing the consumption ratios presented in Figure 6 , it can be seen that for vehicle $\mathrm{C}$ the most economical fuel is ethanol and for vehicle $\mathrm{A}$ the fuel having the lowest cost per kilometer is commercial gasoline, as shown in Figure 8 below.

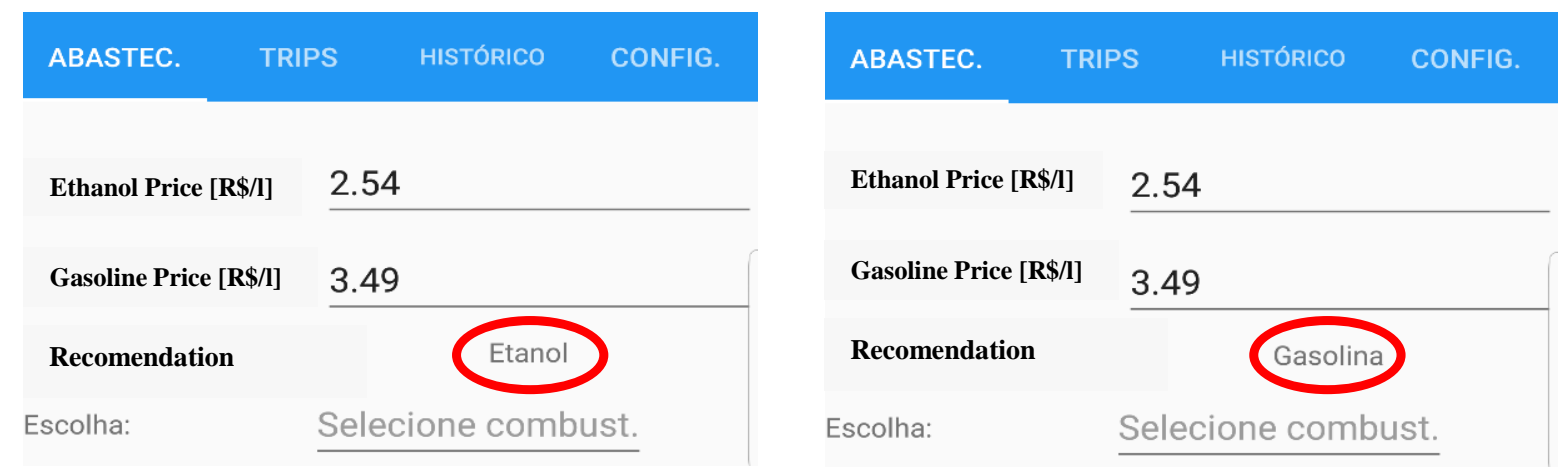

Figure 8. Indication of most economic fuel choice for each vehicle - (left: Vehicle C) - (right: Vehicle A)

\subsection{FUNCTION TO BE IMPLEMENTED}

Given that the tool is still in development some features that are very interesting and useful for the user are still in the implementation phase, nevertheless such functionalities will be better explained below.

\subsubsection{Savings}

As previously stated, the user does not have the information on the environmental impact generated by the use of the vehicle within his daily life in a simple and clear way. One of the functionalities of the tool being developed integrates a calculation of the mass of $\mathrm{CO}_{2}$ and a calculation of the amount of money saved by the driver with respect to his choices of fuel and vehicle use. Such a feature uses the consumption data to calculate the volume of each fuel needed to cover the distance traveled and thus determine the mass of $\mathrm{CO}_{2}$ that was avoid emitting given the use of the green fuel instead of the fossil fuel. It is important to note that this mass of $\mathrm{CO}_{2}$ is calculated considering the whole production chain, in other words is a well to wheel emission for each fuel [7]. For the economic side the logic is the same, but the calculation is made based on fuel prices at the time of refueling rather than the mass of $\mathrm{CO}_{2}$. Figure 9 below illustrates within the economy tab both the proposed ecology and economic aspects 

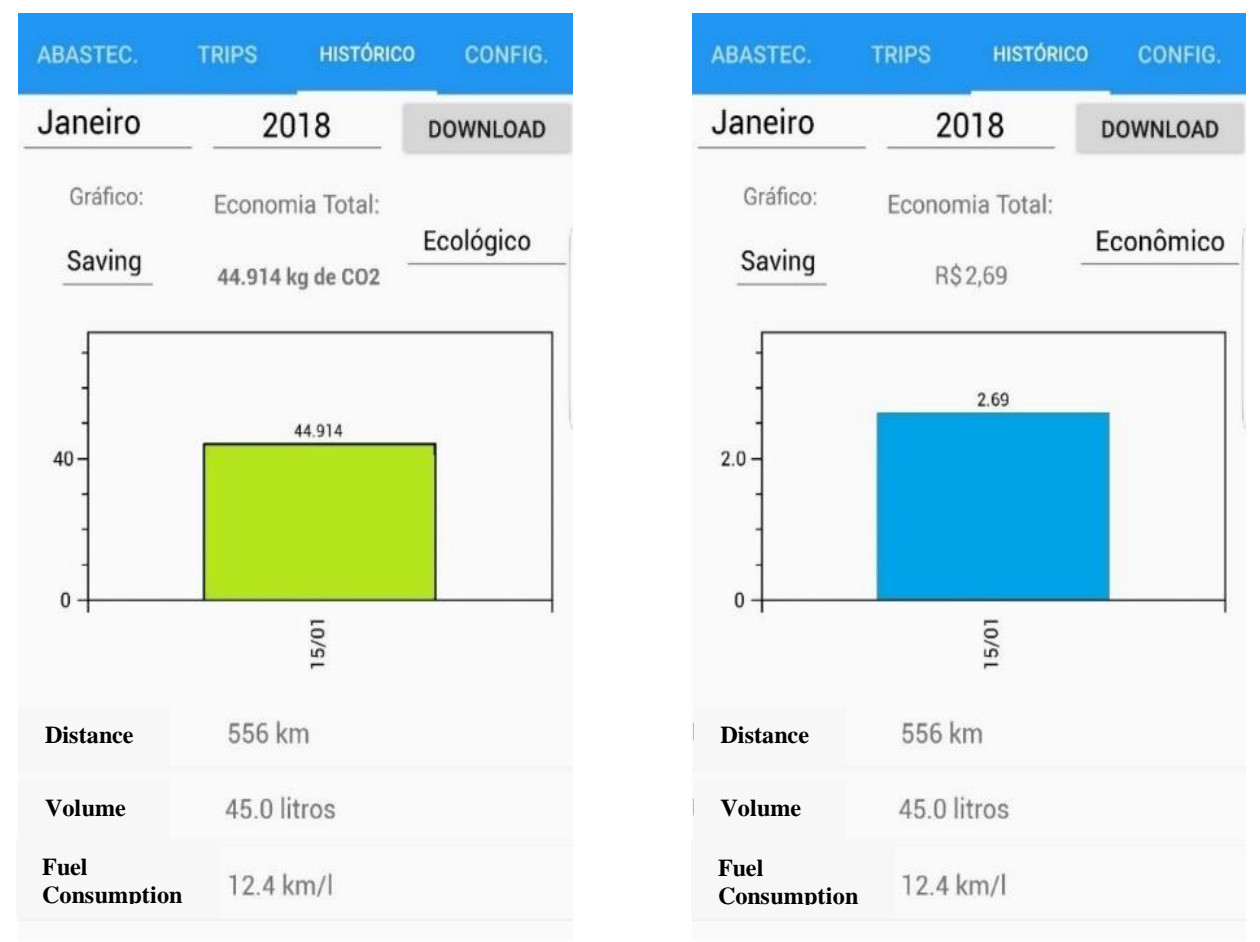

Figure 9. Tab showing the financial saving and the ecological saving

\subsubsection{Maintenance}

As said before the maintenance is a question that has influence on the average consumption of the vehicle, besides it is often a process that if done at the right time can mitigate future problems. It is useful for the user to have an accurate diagnosis of the vehicle components easily and quickly. This diagnosis is made through the collection of both the fault code available in the OBD II standard and the analysis of other information obtained through the CAN bus. After this data collection and faults recording, this information is processed in order to evaluate the state of conservation of several vehicular components and thus to estimate the necessity or not of the substitution of some component before this one presents errors in the operation. In addition to an analysis of the need to perform predictive maintenance, i.e. evaluation of the possibility of future failure and thus replacement of the component before failure, the system is also useful to identify possible causes of failures that are occurring and thus facilitate the corrective maintenance of the vehicle. 


\subsubsection{Tank Level Sensor Adaptation}

A very important feature of the proposed tool is a tank level sensor-learning algorithm by continuously updating the level curve using the volume data refueled and volume consumed per vehicle trip. The algorithm has a learning phase where it compares the variation in the tank level percentage to the user input on the volume refueled or the acquired data about fuel consumption and tank total volume, which is a manufacturer known data, and with the recurring events create a new level curve for the vehicle. For example, if a driver indicates a 40 liter refuel, given that his vehicle has a 50 liter tank, it would be expected a $80 \%$ variation in the tank level but due to imprecision the sensor indicates a $75 \%$, then the algorithm creates a new curve using the learned values to correct the sensor measurements. This feature is very interesting because of three main factors: first is that the level indication in the dashboard of the car has scales that usually have a step from $20 \%$ to $25 \%$ or inform the driver of the percentage of fuel in the tank in a very unprecise way. With the use of this updated curve in the application, the driver will have access to a much more precise percentage at any time that it needs. The second reason is that with such greater accuracy of the tank level it is possible to eliminate the need for manual data inputs at the time of refueling events. The third reason is that with this tank-level information more accurate and in possession of the total volume of the tank of the vehicle, it is possible for the driver to check if fuel pump of the station where he is fueling is tampered. This type of fraud, known as volumetric fraud or popularly called "pump fraud", occurs when the establishment changes the display of the pump indicating a larger volume of fuel than the actual one. Thus charging the user more than it would normally be charged. According to data from the Institute of Weights and Measures of São Paulo (IPEM-SP), there were found filling stations with adulteration of up to $11 \%$ in the indicated volume [8], that is, the consumer was paying for each liter but receiving only part of this volume without his knowledge.

\subsubsection{Gas Stations Ranking}

Fuel quality is something that greatly affects vehicle efficiency and user behavior when refueling. The proposed tool solves this problem through a statistical analysis of the data collected continuously by the vehicles. By accessing the CAN network to vehicle failure reports, it is possible to establish parameters to determine the possibility of contamination in the fuel, in addition to crossing the data of the various vehicles that also refueled in that establishment.

Due to the large number of sensors in vehicles, it is possible to infer from the quantity and specificity of each failure if the problem is caused by poor fuel quality, these problems would be connected to the point of supply via GPS location of the moment of refuel. Since several vehicles had similar faults after refueling at a certain establishment, there would be a decrease in the rating of the station proportional to the quantity and severity of the indicated faults and also in relation to the frequency with which they are detected. In addition to failures related to fuel quality, the rating of the establishments will also change due to the possibility of volumetric fraud in the pumps. This kind of fraud would be indicated by divergence of the variation in the level of the tank captured by the level sensor, and the value indicated in the pump display, indicated by the user. It is important to note that this kind of verification can only happen after the level sensor adaptation period, which was explained earlier in this document. 
The ranking of the stations based on the reports of failures would be made available to the user within the application in an interactive map that contains the gas stations in the region in which the driver is, thus allowing him to be aware of his options and to make the best choice when it comes to filling the vehicle. Data on the ranking of fueling stations would also be available to enforcement agencies such as the ANP or the fuel distributors themselves, since a flag association with fuel fraud may interfere with the consumer's opinion of the distributors, who may direct their fuel quality inspections more assertively and faster. Figure 10 illustrates how the visual ranking of the stations in a region is to be visualized, the rank of the stations is given in stars that are inversely proportional to the quantity, the severity of the failures presented by the vehicles that were supplied in the establishment, and the possibility of volumetric fraud.

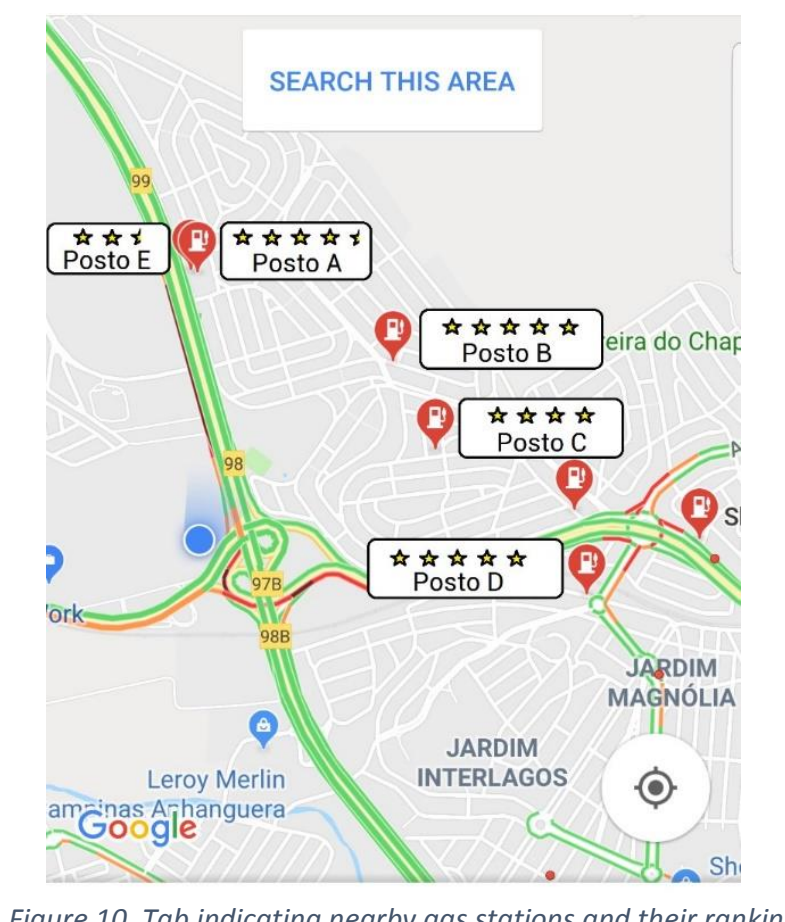

\section{CONCLUSIONS}

Based on all the issues raised in this document, it is necessary to develop technologies that not only increase the efficiency of motor vehicles, but also increase the efficiency in the use of these vehicles by drivers. The tool described here was designed to solve some of the problems mentioned by the interviewees in an ethnographic research, providing the driver with more accurate and updated information that will assist him in his decisions at the time of refueling.

Accurate information on the consumption for each fuel type is important so that the user does not make erroneous decisions based on inaccurate data and ends up using a fuel that does not have an economic or ecological advantage. In addition to the consumption data, the presentation of the environmental impact caused by the use of the vehicle is a way to educate the driver about the importance of the use of biofuel for the environment and for the country, given the commitments made during COP21 previously. 
In this way, the tool proposed in this document is a way to give the user the possibility of contributing actively to the socio-environmental well-being of the community in which it is included, through the most efficient use of its vehicle. Through the direct and indirect supervision of possible fraud at gas stations, given that the reduction in the number of suspect stations, the market itself will lead consumers to gas stations with better ranking, indirectly inhibiting illegal practices in gas stations and thus closing the cycle of the three spheres.

\section{REFERENCES}

[1] World Energy Council. World Energy Resources. WEC, London, 2016.

[2] International Energy Agency. Key World Energy Statistic. IEA, Paris, 2017

[3] Sindicato Nacional da Indústria de Componentes para Veículos Automotores. Relatório de Frota Circulante. Sindipeças, São Paulo, 2018.

[4] Agência Nacional do Petróleo. Panorama de Abastecimento. ANP, Rio de Janeiro, 2017. [5] FARINA, E.; RODRIGUES, L. A Importância de Diretriz para os Biocombustíveis. Revista Opiniões, ano 15, número 54, divisão C, pp 22-24, Out-Dez 2017.

[6] PRUDENTE, C. H. Estudo da Qualidade da Gasolina em Postos de Abastecimento da Cidade de Cândido Mota. Trabalho de Conclusão de Curso - Instituto Municipal de Ensino Superior de Assis; Assis, São Paulo, 2010.

[7] MACEDI, I.C., SEABRA, J.E., SILVA, J.E. Greenhouse gases emissions in the production and use of ethanol from sugarcane in Brazil: the 2005/2006 averages and prediction for 2020. Biomass and Bioenergy 32, 582-595, 2008.

[8] G1 São Paulo. Postos são fechados por fraudar venda de combustíveis em São Paulo. Available at: http://www.ipem.sp.gov.br. Accessed: April 2018. 